\title{
Evaluation of functional parameters, patient-reported outcomes and workload related to continuous urinary bladder irrigation after transurethral surgery
}

\author{
Anja Christina Reichelt ${ }^{1}$, Franz Friedrich Dressler ${ }^{1,2}$, Christian Gratzke ${ }^{1}$, Arkadiusz Miernik ${ }^{1}$, \\ Dominik Stefan Schoeb ${ }^{1}$
}

${ }^{1}$ Faculty of Medicine, Department of Urology, Medical Center - University of Freiburg, Freiburg, Germany; ${ }^{2}$ Faculty of Medicine, Institute of Pathology, University Medical Center Schleswig Holstein Lübeck Campus, Ratzeburger Allee, D-23538 Lübeck, Germany

Contributions: (I) Conception and design: DS Schoeb; (II) Administrative support: C Gratzke, A Miernik; (III) Provision of study materials or patients: C Gratzke, A Miernik, DS Schoeb; (IV) Collection and assembly of data: AC Reichelt, FF Dressler, DS Schoeb; (V) Data analysis and interpretation: AC Reichelt, FF Dressler, DS Schoeb; (VI) Manuscript writing: All authors; (VII) Final approval of manuscript: All authors.

Correspondence to: Dominik Stefan Schoeb, MD, MHBA. Faculty of Medicine, Department of Urology, Medical Center - University of Freiburg, Hugstetterstr. 55, D-79106 Freiburg, Germany. Email: Dominik.stefan.schoeb@uniklinik-freiburg.de.

Background: Continuous saline bladder irrigation (CBI) is a common procedure after transurethral surgery and to treat gross hematuria. We conducted this study to gather data on parameters of CBI, medical staff's work load associated with CBI monitoring, patients' feeling of safety and of patients' impairments during CBI.

Methods: We observed CBI taking place after transurethral surgery for a 2-9-hour period. Patients were asked to rank how safe they felt, general impairments and impaired mobility. Irrigation parameters and complications were documented at least every 30 minutes. The staff's workload was evaluated through the frequency of visits and presence time.

Results: The patients' mobility was notably reduced with an average of $10.5 \% \pm 16.7 \%$ of time spent outside of bed, pain was low (mean $0.60 \pm 1.15)$. Patients felt very safe with CBI $(8.8 \pm 1.9)$, hardly impaired

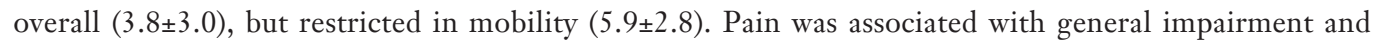
impaired mobility. Clot retention occurred in 5 patients. Average irrigation speed was $9.46 \pm 8.69 \mathrm{~mL} / \mathrm{min}(0$ to $86.7 \mathrm{~mL} / \mathrm{min}$ ). Urine bags were emptied on average every $2.2 \pm 1.2$ hours. Patients were visited by medical personnel 1 to 11 times.

Conclusions: CBI remains an improvable procedure in terms of the irrigation process itself to prevent complications, the patients' feeling of safety and comfort during CBI and the amount of work associated with its monitoring. We have provided parameters for the implementation of more individualized CBI monitoring.

Trial registration: German Clinical Trial Registry; DRKS00023707; Registered retrospectively November 25 2020, https://www.drks.de/drks_web/navigate.do?navigationId=trial.HTML\&TRIAL_ ID=DRKS00023707

Keywords: Urologic surgical procedures; hematuria; continuous saline bladder irrigation; bladder

Submitted Feb 25, 2021. Accepted for publication May 13, 2021.

doi: $10.21037 /$ tau-21-165

View this article at: https://dx.doi.org/10.21037/tau-21-165

\section{Introduction}

Continuous bladder irrigation (CBI) is a common procedure after transurethral surgery $(1,2)$, open prostatectomy (3), and is also performed in cases of spontaneous gross hematuria, e.g., due to bleeding from a malignancy in the urinary tract. It is advocated to prevent clot formation and retention, maintain 
the patency of the drainage catheter lumen, to flush out small clots and control bleeding (4). CBI is usually carried out using normal saline and a three-way Foley catheter over two days $(4,5)$. The inflow must be continuously calibrated to the blood concentration of the outflow drainage in order to sufficiently prevent intravesical blood clot formation. In addition, an obstruction in the outflow can quickly cause the bladder to fill uncontrollably, thus raising the risk of bladder perforation (6) and causing the patient pain and discomfort. Resulting complications often require surgical interventions such as transurethral clot evacuation or even open surgical repair of a bladder perforation. It is therefore imperative to closely monitor CBI to prevent such complications and avoid unnecessary surgical interventions. CBI is therefore part of nursing training in urology (7) to identify and solve technical problems (e.g., tube obstruction) without delay $(8,9)$.

However, although it is a widely applied procedure carrying the inherent risk for various complications, the irrigation fluid flow rate is still monitored manually and roughly estimated by the nurse. In addition, the intensity of hematuria is assessed by visually inspecting the drainage fluid's color. Moreover, it is often the nurse's experience that determines how often they decide to monitor bladder irrigation and thus their patient's condition (9) as long as there is still no technological solution for continuous monitoring. There is no objective data available regarding average irrigation parameters, the workload associated with monitoring, bladder irrigation, and of patients' feeling of safety and impairments caused by the irrigation.

To provide this data, we carried out an observational prospective study to obtain this information by continuously monitoring functional parameters during bladder irrigation as well as interviewing patients undergoing bladder irrigation after transurethral surgery. We present the following article in accordance with the STROBE reporting checklist (available at https://dx.doi.org/10.21037/tau-21-165).

\section{Methods}

\section{Study design and patients}

This study was approved by the Institutional Ethics Committee of the University of Freiburg Germany (Project-ID 9/18) and performed in accordance with the ethical standards laid down in the 1964 Declaration of Helsinki and its later amendments. All participants gave their written consent prior to their inclusion in the study.
Between August 2018 and March 2020, informed consent was obtained from 90 patients prior to inclusion in our study in the Department of Urology at the Medical Center University of Freiburg. All patients underwent transurethral surgery due to prostatic hyperplasia [transurethral resection of the prostate (TUR-P) or holmium laser enucleation of the prostate (HoLEP)] or non-muscle invasive bladder cancer [transurethral resection of the bladder (TUR-B)] and received a bladder catheter for continuous bladder irrigation immediately after their surgery was completed. According to the standard postoperative protocol, the CBI system remained in place for at least 48 hours after surgery. Patients were monitored during this time by specialized urological nursing staff. During the study period, the average ratio was 1 nurse supported by 1 nursing student for 11 patients. The nursing staff adjusted the bladder irrigation's inflow rate to correspond with the amount of postoperative bleeding.

\section{Obtained data}

Age was documented as demographic data. Medical backgrounds were collected through the documentation of type of surgery; initial ultrasound findings including prostate size and post void residual urine volume, and comorbidities. The risk of bleeding was evaluated by relying on the intake of therapeutic anticoagulation and antiplatelet drugs. Irrigation conditions were documented including catheter diameter and type, preoperative catheter requirement, height of the irrigation bag above bladder level, as well as day after surgery. Patient-reported outcomes (PROs) such as feeling of safety during CBI monitoring (0 very unsafe - 10 very safe), and general impairment as well as impaired mobility ( 0 none -10 max. impairment) due to CBI were collected using standardized questionnaires. Pain was assessed via the visual analogue scale (VAS) (9). The questionnaire also included questions regarding the implementation of an electronic surveillance system focusing on expected additional mobility impairment $(0$ none - 10 max. impairment), expected additional feeling of safety ( 0 very unsafe -10 very safe) as well as the preferred amount of data given to the patient at bedside ( 0 none information - 10 max. information) (Appendix 1).

\section{Observation procedure}

All patients were observed for 2 to 9 hours. Observation continued as long as the irrigation system was attached to the patient regardless of the irrigation speed. At the 
beginning of the observation, patients were interviewed regarding their feeling of safety, general impairment and impaired mobility. Irrigation parameters were documented at least every 30 minutes or in the event of flow rate adjustments on a standardized file including flow rate adjustments carried out by staff (none, up, down), weight of the irrigation fluid and urine bag, calculated flow rate, emptying the urine bag or bag changes, and any discolored outflow (actual, average, maximum). Discoloration was categorized as: $0=$ clear irrigation, $1=$ slightly red coloration, $2=\mathrm{dark} \mathrm{red} / \mathrm{residual}$ blood and $3=\mathrm{bright} \mathrm{red} / \mathrm{active}$ bleeding. Moreover, common complications including clot retention, gastrointestinal or genital symptoms and any other events were documented. The patient's mobility and comfort were objectified through the time spent outside of bed.

The staff's workload due to monitoring bladder irrigation was documented through the frequency of visits and presence time of nurses and doctors in the patient's room.

\section{Statistical analysis}

Statistical calculations were performed using Microsoft Excel 2010 Version 14.0 (Microsoft Corp, Redmond, WA, USA) and IBM SPSS Statistics Version 23 (IBM Corp, Armonk, NY, USA). Descriptive statistics were used: percentages, means and standard deviation. We assessed linear univariate regressions and calculated the Pearson correlation coefficient to evaluate the correlation between subjective impairment and feeling of safety, as well as between pain and safety and pain and impairment. Chisquare-test was used to compare patient groups divided by surgical procedure regarding categorical variables. Student's t-test was used to compare differences in age, residual urine and prostate size in patient groups subdivided by surgical procedure, as well as feeling of safety and impairment between patient groups divided by their status of irrigation. Statistically significant group differences were considered at $\mathrm{P}<0.05$.

\section{Results}

\section{Patient demographic}

The average age of patients was $70.9 \pm 9.9$ years ranging from 40 to 90 years. Of the included patients, 29 underwent transurethral resection of the bladder, 36 transurethral resection of the prostate and 24 holmium enucleation of the prostate. Information on therapeutic anticoagulation, platelet inhibition, preoperative initial ultrasound findings and if a catheter was required prior to surgery is listed for each type of surgery in Table 1 . There were no significant group differences.

\section{Functional irrigation parameters}

The average height of the irrigation fluid was $101 \pm 3.8$ $\mathrm{cm}(90-105 \mathrm{~cm}), 65(72.2 \%)$ patients had a catheter sized Ch 24, 25 (27.8\%) patients had a catheter sized Ch 20. $12.2 \%$ of patients were observed on the day of surgery, $81.1 \%$ on the first day after surgery, and the remaining $6.7 \%$ on day 2 or later after surgery. The mean value was $9.46 \pm 8.69 \mathrm{~mL} / \mathrm{min}$ with a range of 0 to $86.7 \mathrm{~mL} / \mathrm{min}$. The irrigation flow rate was raised in 38 patients 1 to 3 times and lowered in 43 patients 1 to 3 times. Active bleeding involving bright red blood in the irrigation fluid (category 4) was recorded in only 5 patients, while residual blood was detected in the irrigation fluid of 20 patients. We documented clear irrigation or only traces of blood requiring only minimal irrigation in the remaining patients. Over the total observation time, irrigation was clear in $62.4 \%$ thereof, in $30.6 \%$ there were traces of blood, in $6.3 \%$ we noted dark red coloration representing suspending bleeding, and the irrigation was caused by active bleeding $0.7 \%$ of the time (Figure 1). There were 42 cases of catheter-related complications. Five patients suffered clot retention requiring reoperation entailing transurethral coagulation of the bleeding in 1 patient, and catheterbased clot evacuation and placement of a new irrigation catheter in 4 . One patient needed surgical revision due to relevant postoperative bleeding. Furthermore, 37 patients reported genital discomfort at times (Table 2). There were no significant group differences regarding complications.

In 10 patients the irrigation bags were emptied, and had to be replaced after an average observation time of 4.1 hours ( \pm 1.9 hours). In one patient the bag was emptied twice and had to be replaced again after 2 hours.

\section{Patient impairment}

Our patients' mobility was notably reduced, with an average of only $10.5 \% \pm 16.7 \%$ of the time spent outside of bed (ranging from no time (18 patients) to $94.4 \%$ outside of bed). Average pain was very low with a mean of $0.60 \pm 1.15$, ranging from 0 to 8 . On average, the patients felt very safe with the irrigation $(8.8 \pm 1.9)$, barely impaired 
Table 1 Patient information on age, therapeutic coagulation, platelet inhibition, initial ultrasound findings and whether a catheter had been in place before surgery subdivided by groups according to type of surgery

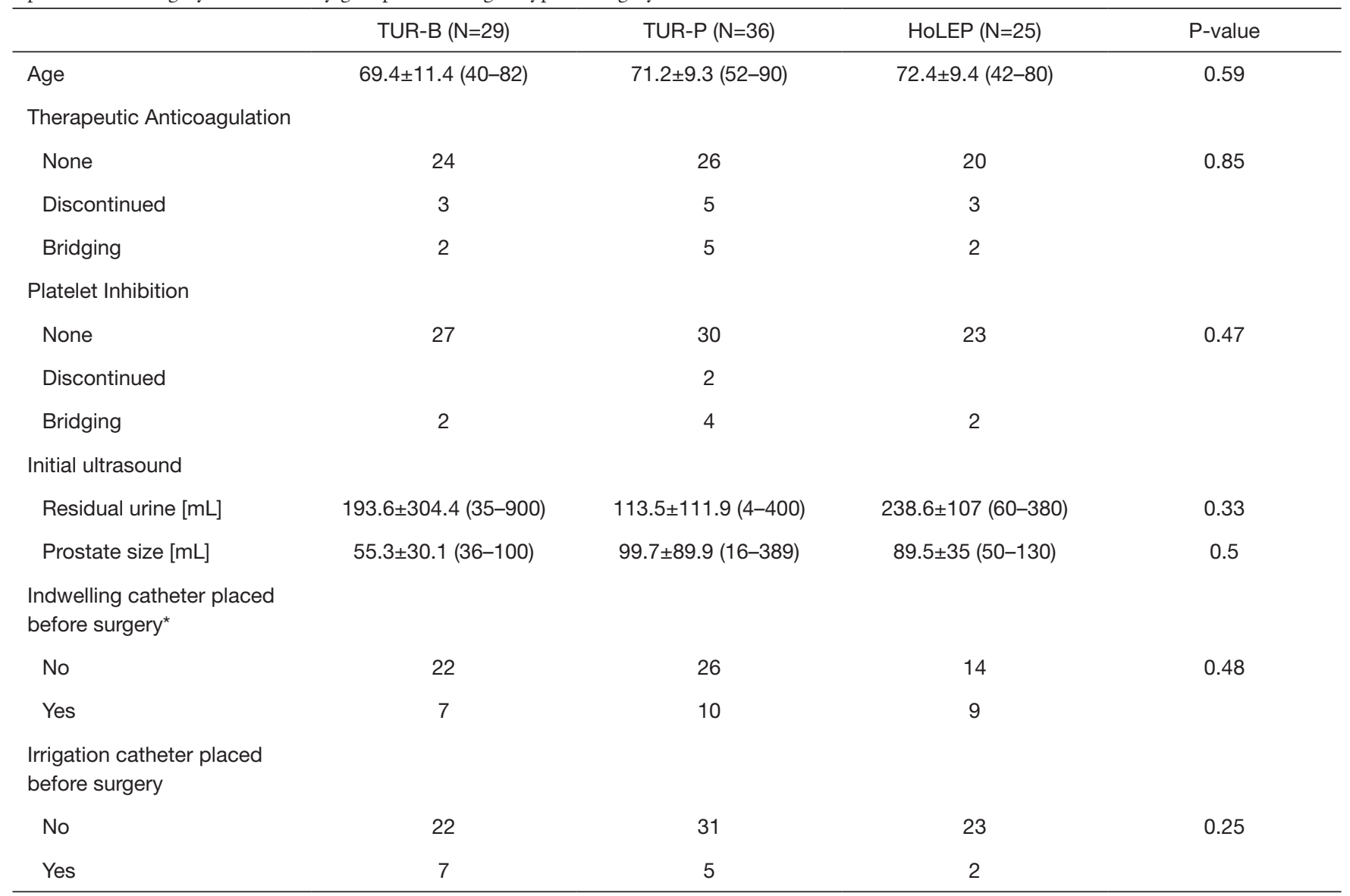

${ }^{*}$ Catheter placed 3 or more days ago. TUR-B, transurethral bladder resection; TUR-P, transurethral prostate resection; HoLEP, Holmium Laser Resection of the Prostate.

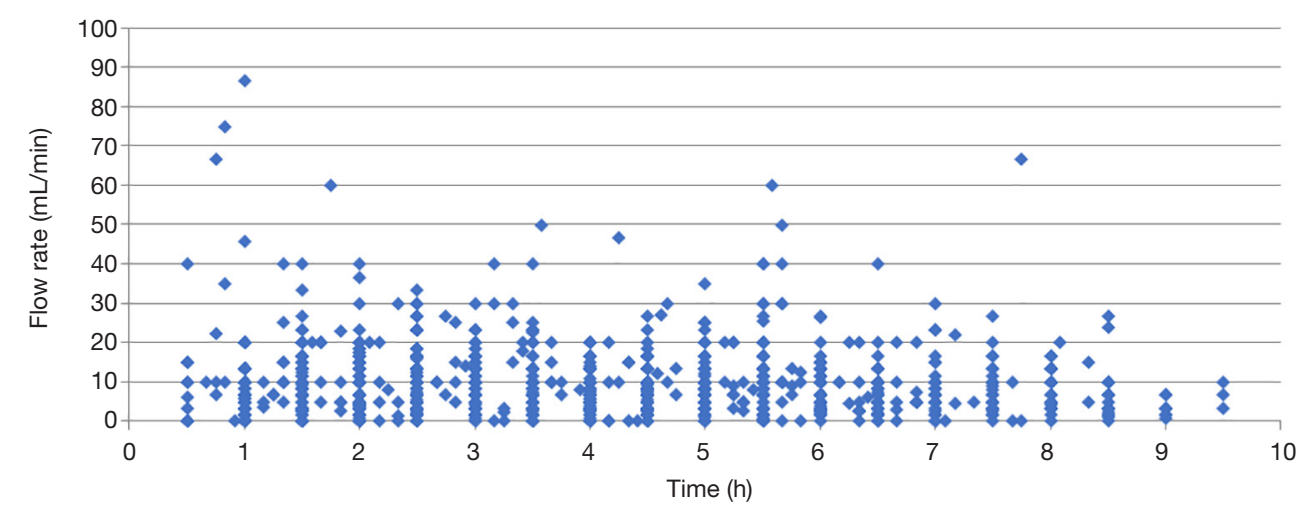

Figure 1 Flow rate [mL/min] of Continuous bladder irrigation (CBI) inflow over point in observed time [h]. 
Table 2 Postoperative complications according to Clavien-Dindo-Classification throughout the observation period subdivided by groups according to type of surgery

\begin{tabular}{|c|c|c|c|c|}
\hline Complications & TUR-B (N=29) & TUR-P (N=36) & HoLEP $(\mathrm{N}=25)$ & $P$ value \\
\hline $\begin{array}{l}\text { Bleeding }{ }^{*} \text { without indication for } \\
\text { surgical revision }\end{array}$ & 2 & & 3 & 0.81 \\
\hline Diarrhoea & 2 & 3 & 1 & \\
\hline Genital discomfort & 13 & 10 & 15 & \\
\hline Bladder spasm & & & 1 & \\
\hline \multicolumn{5}{|l|}{ Grade IIIa } \\
\hline Surgical revision due to bleeding & & 1 & & \\
\hline Surgical revision due clot retention & 1 & & & \\
\hline
\end{tabular}

*Bleeding was defined as only blood visible in the irrigation outflow. TUR-B, transurethral bladder resection; TUR-P, transurethral prostate resection; HoLEP, Holmium Laser Resection of the Prostate.

overall (3.8 \pm 3.0$)$, but restricted in their mobility $(5.9 \pm 2.8)$. We observed a significant negative correlation between subjective impairment and feeling of safety $(\mathrm{R}=-0.3$; $\mathrm{P}=0.002)$. All patients who experienced post-surgical bleeding at the beginning of observation $(n=3)$ felt very safe with the irrigation (8-10); one of them required surgical revision. Patients whose irrigation was already clear (44.4\%) felt more impaired by the irrigation and less safe than those whose irrigation still contained a low quantity of blood (category $1 ; 39 \%)(\mathrm{P}=0.05, \mathrm{P}=0.03)$. There were no differences to the patients with residual blood in the irrigation $(13 \%)(\mathrm{P}=0.11 ; \mathrm{P}=0.10)$. Patients who reported pain $(35.6 \%)$ felt more impaired generally and mobilitywise by the irrigation than those without pain $(\mathrm{P}=0.005$, $\mathrm{P}=0.05)$.

\section{Questionnaire on the implementation of an electronic surveillance system}

On average the patients claimed they would feel quite safe with an electronic surveillance system $(6.5 \pm 2.5)$ and not substantially impaired additionally $(4.3 \pm 3.2)$. The amount of the preferred information presented to the patient at bedside varied strongly across the group $(4.7 \pm 3.7)$.

\section{Staff's workload}

Patients were visited by medical personnel 1 to 11 times during the observation period, on average every $1.04 \pm 0.8$ hours: the urine bag had to be emptied every $2.2 \pm 1.2$ hours. Visits were carried out by nursing staff $86.6 \%$ of the time (doctors $8.3 \%$, round $5.1 \%$ ). The average visit by medical personnel lasted $2.5 \pm 2.7$ minutes.

\section{Pain management}

All patients in this study were routinely given Ibuprofen $600 \mathrm{mg}$ twice a day for the first two postoperative days. In case of VAS $>5$, they received Metamizol $1 \mathrm{~g}$ intravenously. No other analgesics were administered in this study.

\section{Discussion}

This study is, to our knowledge, the first to assess and objectify functional parameters of postoperative transurethral urinary bladder irrigation, patient-reported outcomes associated with bladder irrigation, and the medical staff's time spent monitoring irrigation. Due to significant anatomical differences between the male and 
female lower urinary tracts, we decided to include only one gender in this study. As it is usually men who undergo CBI due to prostate surgery in our clinic, we enrolled only men in this study.

Our study shows that after transurethral surgery, most patients reported subjectively restricted mobility due to bladder irrigation. The German initiative QUIPS has delivered data on the comparison of pain-related functional impairments on the first postoperative day in different surgical subspecialties, and reveals that in urology, the focus is on pain-related impaired mobilization (10). Postoperative pain can influence the patient's recovery, and its management often requires a multidisciplinary approach to achieve the patient's effective rehabilitation (11). However, further analysis confirmed that pain is also a factor influencing patients' perceptions of general and mobility restrictions. While patients perceive bladder irrigation as a very safe procedure, our analysis showed that more strongly perceived impairment is associated with feeling less safe. An effective postoperative pain therapy could therefore strengthen patients' feeling of comfort and safety during the irrigation process.

In this study, the ratio of registered nurses, although supported by one nursing student, to patients was about 1 to 11 , which is a bit higher than the average ratio for German acute care hospitals cited by the RN4CAST study, which surveyed nurses and patients in several general acute care hospitals in 12 European countries (12). According to this study, approximately 20 patients are treated on a general urological ward of whom about $50 \%$ undergo bladder irrigation. We show that the average bladder-irrigation visit lasted 2.5 minutes and was carried out every hour, although we did not document whether the visits were made by registered nurses or students. Given that supervising CBI requires experience to identify complications and the need for adjustments (7-9) almost half of registered nurses' time would be consumed only by bladder irrigation if they alone were doing it. There is evidence that a heavy staff workload is associated with patient dissatisfaction $(13,14)$. Aiken et al. (15) showed that a one-patient increase in a nurse's workload raises an inpatient's 30-day mortality rate by $7 \%$. CBI might thus provide an adequate target for significantly reducing nurses' workload while improving the safety and quality of their work.

In our study, clot retention occurred in 5 patients despite continuous irrigation-in 4 patients (4.5\%) already on the first postoperative day. This number is comparable to that reported by Nojiri et al. in their study (2), as they observed clot retention in $4.4 \%$ after TUR-P during the immediate postoperative period, yet our percentage is somewhat higher than in studies evaluating clot retention after HoLEP, which ranged from only $0.9 \%$ to $1.4 \%$ $(16,17)$. This indicates that the irrigation monitoring process still has room for improvement, both in terms of the nursing staff's workload and the irrigation process itself. Studies have shown that especially the documentation of fluid balance in bladder irrigation is often faulty $(18,19)$ an important step to identify intact urine production and potential blockages in the catheter (20). In intensive care, highly technical monitoring systems have become indispensable (21). Such monitoring setups on a normal ward might help prevent fatal complications (22) and lighten the nursing staff's workload. Our data shows that a significant workload is dedicated to maintaining and monitoring CBI in patients after transurethral surgery. Furthermore, patients suffering from severe hematuria due to bladder tumors or other bladder injuries might benefit from permanent electronic monitoring. As our study shows, patients appear willing to accept electronic monitoring while undergoing CBI; they might even gain additional trust through such a system. We provide here for the first time objective irrigation parameters that can be considered a first step in implementing automated, perhaps individualized bladder irrigation monitoring on urological wards. Further scientific research by a multi-institutional consortium is undergoing to develop and then test such a device first in patients.

This study has several limitations. We only considered one time interval that differed between patients during the irrigation process in this study, focusing especially on the first postoperative day. Our data analysis did not address the comparison of different catheter diameter sizes, and our data only accounts for irrigation fluid at room temperature.

We have addressed the three most common surgical procedures after which CBI is performed at our clinic. These data might differ on other surgical procedures. In addition, every patient undergoing HoLEP in our department undergoes CBI, TUR-P or TUR-B by default. Moreover, only men were included in this study. Irrigation parameters und pain ratings, as well as subjective restrictions and impairments may differ in women. We also cannot exclude a bias brought about by the interviewer.

Our data has therefore to be supplemented by studies observing the entire irrigation period and specific data on the day of surgery and respective postoperative days. Moreover, data on women undergoing CBI and CBI 
after other procedures is required. Furthermore, as the nurses were informed about the ongoing study, we cannot exclude an information bias which could have led to more frequent or extensive visits. To avoid a bias caused by interviewers, future studies could administer only self-rating questionnaires to be completed by patients at certain time intervals.

\section{Conclusions}

CBI is a commonly applied urological procedure associated with a low degree of discomfort and pain for the patient, but also with highly impaired patient mobility. More intensive monitoring might help us prevent complications while improving patient satisfaction. We consider the parameters this study provides as a first step toward enabling the development of individualized monitoring.

\section{Acknowledgments}

Funding: Funded by the German Federal Ministry of Education and Research (BMBF); Project title: VisIMon (Funding number: 16SV7862).

\section{Footnote}

Reporting Checklist: The authors have completed the STROBE reporting checklist. Available at https://dx.doi. org/10.21037/tau-21-165

Peer Review File: Available at https://dx.doi.org/10.21037/ tau-21-165

Data Sharing Statement: Available at https://dx.doi. org/10.21037/tau-21-165

Conflicts of Interest: All authors have completed the ICMJE uniform disclosure form (available at https://dx.doi. org/10.21037/tau-21-165). Anja Reichelt and Dominik S. Schoeb: Funding by the German Federal Ministry of Education and Research (BMBF). Arkadiusz Miernik: research funding: Federal Ministry of Education and Research (BMBF), DE, coverage of travel expenses: German Association of Urology (DGU), DE, European Association of Urology (EAU), NL; advisor: KLS Martin GmbH, DE, Dornier MedTech Europe GmbH, RichardWolf GmbH, DE, KarlStorz SE \& Co. KG, DE, Lisa laser OHG, DE, Boston Scientific, USA, Dornier MedTech Europe GmbH,
DE, Medi-Tate Ltd., IL; reviewer: Ludwig Boltzmann Gesellschaft, A; royalties: Walter de Gruyter, DE, Springer Science+Business Media, DE. The other authors have no conflicts of interest to declare.

Ethical Statement: The authors are accountable for all aspects of the work in ensuring that questions related to the accuracy or integrity of any part of the work are appropriately investigated and resolved. This study was approved by the Institutional Ethics Committee of the University of Freiburg Germany (Project-ID 9/18) and performed in accordance with the ethical standards laid down in the 1964 Declaration of Helsinki and its later amendments. All participants gave their written consent prior to their inclusion in the study.

Open Access Statement: This is an Open Access article distributed in accordance with the Creative Commons Attribution-NonCommercial-NoDerivs 4.0 International License (CC BY-NC-ND 4.0), which permits the noncommercial replication and distribution of the article with the strict proviso that no changes or edits are made and the original work is properly cited (including links to both the formal publication through the relevant DOI and the license). See: https://creativecommons.org/licenses/by-nc-nd/4.0/.

\section{References}

1. Edwards LE, Bucknall TE, Pittam MR, et al. Transurethral resection of the prostate and bladder neck incision: a review of 700 cases. Br J Urol 1985;57:168-71.

2. Nojiri Y, Okamura K, Kinukawa T, et al. Continuous bladder irrigation following transurethral resection of the prostate (TURP). Nihon Hinyokika Gakkai Zasshi 2007;98:770-5.

3. Shaheen A, Quinlan D. Feasibility of open simple prostatectomy with early vascular control. BJU Int 2004;93:349-52.

4. Végh A, Magasi P. The importance of closed bladder irrigation in prostatectomy. Acta Chir Hung 1988;29:137-41.

5. Attah CA. Effect of continuous irrigation with normal saline after prostatectomy. Int Urol Nephrol 1993;25:461-7.

6. Avellino GJ, Bose S, Wang DS. Diagnosis and management of hematuria. Surg Clin North Am 2016;96:503-15.

7. Scholtes S. Management of clot retention following urological surgery. Nurs Times 2002;98:48-50.

8. Manley BJ, Gericke RK, Brockman JA, et al. The pitfalls 
of electronic health orders: development of an enhanced institutional protocol after a preventable patient death. Patient Saf Surg 2014;8:39.

9. $\mathrm{Ng} \mathrm{C}$. Assessment and intervention knowledge of nurses in managing catheter patency in continuous bladder irrigation following TURP. Urol Nurs 2001;21:97-8, 1017, 110-1.

10. Meissner W. QUIPS: quality improvement in postoperative pain management. Z Evid Fortbild Qual Gesundhwes 2011;105:350-3.

11. Kehlet H. Postoperative pain, analgesia, and recoverybedfellows that cannot be ignored. Pain 2018;159:S11-6.

12. Aiken LH, Sloane DM, Bruyneel L, et al. Nurses' reports of working conditions and hospital quality of care in 12 countries in Europe. Int J Nurs Stud 2013;50:143-53.

13. Aalto P, Karhe L, Koivisto AM, et al. The connection between personnel resources with work loading and patient satisfaction on in-patient wards. J Nurs Manag 2009; 17:135-42.

14. Goh ML, Ang EN, Chan YH, et al. Patient satisfaction is linked to nursing workload in a Singapore hospital. Clin Nurs Res 2018;27:692-713.

15. Aiken LH, Sloane DM, Bruyneel L, et al. Nurse staffing

Cite this article as: Reichelt AC, Dressler FF, Gratzke C, Miernik A, Schoeb DS. Evaluation of functional parameters, patient-reported outcomes and workload related to continuous urinary bladder irrigation after transurethral surgery. Transl Androl Urol 2021;10(7):2921-2928. doi: 10.21037/tau-21-165 and education and hospital mortality in nine European countries: a retrospective observational study. Lancet 2014;383:1824-30.

16. Kim M, Piao S, Lee H-E, et al. Efficacy and safety of holmium laser enucleation of the prostate for extremely large prostatic adenoma in patients with benign prostatic hyperplasia. Korean J Urol 2015;56:218.

17. Kuo RL, Kim SC, Lingeman JE, et al. Holmium laser enucleation of prostate (HoLEP): the Methodist Hospital experience with greater than 75 gram enucleations. J Urol 2003;170:149-52.

18. Cutts B. Developing and implementing a new bladder irrigation chart. Nurs Stand 2005;20:48-52.

19. Nazli A, Brigham-Chan F, Fernandes M, et al. Adequacy of fluid balance chart documentation on wards. Clin Med (Lond) 2016;16:s21.

20. Foxley S. Indwelling urinary catheters: accurate monitoring of urine output. Br J Nurs 2011;20:564, 566-9.

21. Neideen T. Monitoring devices in the intensive care unit. Surg Clin North Am 2012;92:1387-402.

22. Michard F, Sessler D. Ward monitoring 3.0. Br J Anaesth 2018;121:999-1001. 


\section{Supplementary}

Appendix 1 English translation of the questionnaire used in this study to record the patient related parameters.

\begin{tabular}{|c|c|}
\hline Initial Questions & Answer \\
\hline $\begin{array}{l}\text { How secure do you feel with the monitoring of the irrigation by the nursing staff? }(0=\text { not secure at all } \ldots \\
10=\text { very secure) }\end{array}$ & \\
\hline $\begin{array}{l}\text { Would you prefer an electronic permanent surveillance? } \\
(0=\text { no, } 1=\text { yes, } 2=\text { neutral) }\end{array}$ & \\
\hline $\begin{array}{l}\text { How secure would you feel with an electronic surveillance system? } \\
(0=\text { not secure at all } \ldots 10=\text { very secure) }\end{array}$ & \\
\hline $\begin{array}{l}\text { How much is your mobility impaired by the irrigation system? } \\
(0=\text { not at all } \ldots 10=\text { max. impairment) }\end{array}$ & \\
\hline $\begin{array}{l}\text { How much do you think an additional tablet size surveillance device would impair your mobility further? } \\
(0=\text { not at all } \ldots 10=\text { max. impairment) }\end{array}$ & \\
\hline $\begin{array}{l}\text { How would much would you agree, that having a video based feedback system would make you feel more } \\
\text { secure? } \\
\text { ( } 0=\text { Max. disagreement } \ldots 10=\text { max. agreement) }\end{array}$ & \\
\hline $\begin{array}{l}\text { How much information about the status of your irrigation would you like to be displayed at your bedside? } \\
\text { ( } 0 \text { =no information } \ldots 10=\text { all available information) }\end{array}$ & \\
\hline
\end{tabular}

\begin{tabular}{|c|c|}
\hline Questions repeated during surveillance & Answer \\
\hline $\begin{array}{l}\text { Type of pain } \\
\text { [0]: no pain } \\
\text { [1]: pain when moving } \\
\text { [2]: constant pain }\end{array}$ & \\
\hline $\begin{array}{l}\text { [0]: bladder cramps occured } \\
\text { [1]: no bladder cramps occured }\end{array}$ & \\
\hline$[\mathrm{X}]$ : Minutes out of bed since last interview & \\
\hline $\begin{array}{l}\text { Location(s) since last interview } \\
\text { [0]: always in bed } \\
\text { [1]: patient room } \\
\text { [2]: smoking } \\
\text { [3]: cafeteria } \\
\text { [4]: walking inside the hospital building } \\
\text { [5]: walking outside the hospital building } \\
\text { [6]: toilet } \\
\text { [7]: other: }\end{array}$ & \\
\hline
\end{tabular}

